\title{
Catumaxomab with Activated T-cells Efficiently Lyses Chemoresistant EpCAM-positive Triple-negative Breast Cancer Cell Lines
}

\author{
MAKOTO KUBO ${ }^{1}$, MASAYO UMEBAYASHI ${ }^{2}$, KANAKO KURATA ${ }^{1}$, HITOMI MORI $^{1}$, MASAYA KAI ${ }^{1}$, \\ HIDEYA ONISHI $^{3}$, MITSUO KATANO ${ }^{3}$, MASAFUMI NAKAMURA ${ }^{1}$ and TAKASHI MORISAKI ${ }^{2}$ \\ ${ }^{1}$ Department of Surgery and Oncology, Graduate School of Medical Sciences, Kyushu University, Fukuoka, Japan; \\ ${ }^{2}$ Fukuoka General Cancer Clinic, Fukuoka, Japan; \\ ${ }^{3}$ Department of Cancer Therapy and Research, Graduate School of Medical Sciences, Kyushu University, Fukuoka, Japan
}

\begin{abstract}
Background/Aim: Epithelial cell adhesion molecule (EpCAM) is expressed in various types of cancer, including breast cancer, and is correlated with metastasis, invasion, therapeutic resistance and prognosis. Moreover, several cell surface markers, such as CD44 and EpCAM, are molecular targets on cancer stem-like cells of breast cancer. The aim of this study was to investigate whether catumaxomab, a clinicalgrade bispecific antibody that binds to both EpCAM on tumor cells and CD3 on T-cells, combined with activated T-cells can eliminate chemoresistant triple-negative breast cancer (TNBC) cells in vitro. Materials and Methods: First, a cell line (MUKBC1) was established from human breast carcinoma cells derived from a patient with chemoresistant and disseminated breast cancer. These EpCAM-positive TNBC cells were almost completely resistant to various drug-mediated cytotoxicities up to a concentration of $10 \mu \mathrm{g} / \mathrm{ml}$. Results: Pre-treatment with catumaxomab and subsequent addition of interleukin-2/OKT3activated autologous T-cells eliminated EPCAM-positive TNBC cells. Conclusion: Catumaxomab combined with activated Tcells may be a potent therapeutic modality to overcome chemoresistant EpCAM-positive TNBC cells.
\end{abstract}

Epithelial cell adhesion molecule (EpCAM, also designated as TACSTD1 or CD326) is a cell surface glycoprotein, which is localized on the basolateral membrane seen in majority of

This article is freely accessible online.

Correspondence to: Dr. Takashi Morisaki, Fukuoka General Cancer Clinic, 3-1-1 Sumiyoshi, Hakata-ku, Fukuoka 812-0018, Japan. Tel: +81922827696, Fax: +81924056376, e-mail: tmorisaki@cancerclinic.jp

Key Words: EpCAM, catumaxomab, chemoresistance, cytokineactivated T-cells, triple-negative breast cancer. normal epithelial tissues or neoplasms derived from epithelia (1). It is also frequently expressed in carcinomas of various origins, including breast, ovary, prostate, lung, colon, pancreas, stomach, neck, and head (2-4). The wide expression of EpCAM on tumor cells suggests that it is a tumorassociated antigen, and it could be of special interest for innovative immunotherapies. Overexpression of EpCAM may promote the proliferation, migration and invasion of breast cancer cells $(2,5)$. EpCAM protein expression is detected in more than $90 \%$ of breast cancers, and high expression levels were found to be associated with poor outcome in several retrospective analyses (6-8).

Triple-negative breast cancer (TNBC) is a subclass of breast tumors that lack estrogen receptor (ER), progesterone receptor $(\mathrm{PgR})$ and human epidermal growth factor receptor type 2 (HER2) expression, as determined by immunohistochemistry (IHC). This specific subtype of TNBC accounts for $12 \%-17 \%$ of breast cancers (9), and patients with TNBC have relatively poor outcomes. EpCAM overexpression was found to be independently associated with poor survival in node-negative patients, and this effect was particularly strong in the subgroup of triple-negative breast cancer, making EpCAM an attractive therapeutic target in this patient population $(7,10,11)$. Schmidt et al. reported that combination therapy using adecatumumab, an EpCAM antibody, and docetaxel was safe, feasible, and potent even in heavily pre-treated advanced-stage breast cancer (12).

Catumaxomab (anti-EpCAM $\times$ anti-CD3) is a trifunctional, monoclonal bispecific antibody, which effectively attaches EpCAM on tumor cells and CD3-specific binding sites on $\mathrm{T}$ cells. In addition, the Fc-fragment of catumaxomab binds to Fc $\gamma$ receptor Type I- and III-positive cells, such as macrophage, dendritic cells, and natural killer cells, and then activates them (13). Jäger et al. described that catumaxomab therapy activated peritoneal $\mathrm{T}$ cells and eliminates EpCAMexpressing tumor cells in malignant ascites (14). 
In this study, an immunotherapy model was established for overcoming chemoresistant TNBC. It was examined whether the combination of a bispecific antibody and activated T-cells can provide rational evidence for a possible therapeutic strategy that can eradicate chemoresistant TNBC.

\section{Materials and Methods}

Reagents. The humanized mouse trifunctional antibody to human EpCAM, catumaxomab (Removab ${ }^{\mathrm{TM}}$ ), was purchased from Fresenius Biotech GmbH (Graefelfing, Germany). For cell imaging, calcein-AM was purchased from Dojindo (Osaka, Japan).

Establishment and characterization of a breast carcinoma cell line from a patient with chemo-refractory metastatic breast cancer. Peripheral blood mononuclear cells (PBMCs) and pleural effusion were obtained from a 33-year-old female patient with metastatic TNBC, who had undergone chemotherapy consisting of anthracycline followed by taxane, and whose disease progressed to formation of malignant pleural effusion with chemoresistance. The patient's PBMCs from leukapheresis for adoptive immunotherapy were cryopreserved at $-80^{\circ} \mathrm{C}$ until it was used. Cells in the pleural effusion were cultured in DMEM/F12 (Life Technologies, Grand Island, NY, USA) supplemented with $10 \%$ foetal bovine serum (Thermo Fisher Scientific, Waltham, MA, USA). In the present study, a cell line (MUK-BC1) was established resembling CSLCs from a patient with metastatic and disseminated TNBC by the primary culture. After establishment of the cell line, the cells were characterized by their surface antigens and drug sensitivity. In vitro cytotoxicity assays were also performed as described below. A written informed consent was obtained from the patient. This study was approved by the Ethic Committee of the Fukuoka General Cancer Clinic.

Monoclonal antibodies and flow cytometry. Surface markers of tumour cells were labelled by direct or indirect immunofluorescence using the following monoclonal antibodies: antiCD44-PE (Immunotech Beckman Coulter, Brea, CA, USA), antiEpCAM-FITC (BioLegend, San Diego, CA, USA), anti-MICA/BPE (R\&D Systems, Minneapolis, MN, USA), anti-ULBP-1 3 (R\&D Systems), anti-CD24 (Beckman Coulter), anti-ClassI, DNAM1-FITC (BioLegend) and goat anti-mouse IgG-Alexa Fluor 488 (Molecular Probes, Eugene, OR, USA). To detect CSC-like markers, detached cells were washed twice in cold phosphatebuffered saline and stained with mouse anti-human FITC-labelled anti-EpCAM for $60 \mathrm{~min}$ at $4^{\circ} \mathrm{C}$. Surface markers on activated Tcells were labelled by direct or indirect immunofluorescence using anti-CD3-FITC, anti-CD16-FITC, anti-CD56-PE (Immunotech Beckman Coulter), and anti-NKG2D-PE (R\&D Systems) monoclonal antibodies for 60 minutes at $4^{\circ} \mathrm{C}$. Fluorescence was detected using an FC500 flow cytometer (Beckman Coulter) and expressed as the relative mean fluorescence intensity (MFI) or percentage of positive cells.

Cell proliferation assay. Cells were treated with different concentrations of various drugs, catumaxomab, or with dimethyl sulphoxide (DMSO) as a vehicle control. DMSO concentrations were $<0.1 \%$. For proliferation assays, cells were cultured in 96-well plates (Becton Dickinson, Franklin Lakes, NJ, USA) at $5 \times 10^{4}$ cells $/ \mathrm{ml}$ in $100 \mu \mathrm{l}$ of medium. Assays were performed over $48 \mathrm{~h}$ with a minimum of five replicates. For drug treatments, cells were treated with different concentrations of catumaxomab $(0.1 \mathrm{pg} / \mathrm{ml}$ to $10 \mathrm{ng} / \mathrm{ml})$ or other drugs $(0.01$ to $100 \mu \mathrm{g} / \mathrm{ml})$, such as iniparib, paclitaxel, gemcitabine, cisplatin, sorafenib, olaparib and celecoxib. Proliferation assays were performed using a WST-8 cell proliferation kit (Dojindo, Osaka, Japan), in accordance with the manufacturer's instructions. Cell proliferation was confirmed by time-lapse imaging of MUK-BC1 cells and autologous activated lymphocytes. Images were acquired every $30 \mathrm{sec}$ for $14 \mathrm{~h}$ using LuminaVision (Mitani Corporation, Tokyo, Japan).

Generation of ex vivo expanded and activated lymphocytes. To prepare effectors cells, cytokine-activated killer T (CAT) cells were induced from PBMCs obtained from healthy volunteers or a patient with written informed consent. The PBMCs were treated with a low concentration of recombinant IL2 (200 U/ml; Chiron, Emeryville, CA, USA) and $5 \mu \mathrm{g} / \mathrm{ml}$ Orthoclone ${ }^{\circledR}$ (OKT3; Janssen-Cilag, Tokyo, Japan), and expanded for 10-14 days to obtain sufficient numbers of activated lymphocytes, including mainly T-cells and a very small number of natural killer cells.

Cytotoxicity assay. To measure the cytotoxicity of CAT cells, an adherent target detachment (ATD) assay that has been described previously was modified and used $(15,16)$. Target cells (5000 per well) were seeded in a flat-bottomed 96 -well plate and incubated overnight to allow adherence. Different concentrations of catumaxomab were added to the target cells, followed by pre-incubation for $48 \mathrm{~h}$. The cells were then washed and cultured with or without activated T-cells (5$10 \times 10^{4}$ cells/well) for a further $4 \mathrm{~h}$. Effectors cells and dead target cells that were detached from the culture surface were removed by washing. To quantify viable adherent cells, WST- 8 reagent solution (from the WST-8 cell proliferation kit) was added to the washed wells, followed by incubation for $1 \mathrm{~h}$ at $37^{\circ} \mathrm{C}$. The absorbance at $450 \mathrm{~nm}$ was then measured using a microplate reader (ImmunoMini NJ-2300; Nalge Nunc International, Rochester, NY, USA). Detached tumor cells were stained with 7-amino-actinomycin D (Becton Dickinson) to confirm that they were not viable.

Calcein-release cytotoxicity assay and cell imaging. Antibodymediated cellular cytotoxicity (ADCC) assays were measured by calcein-AM which was released from lysed tumor cells. Briefly, target cells were resuspended at $1 \times 10^{5}$ cells $/ \mathrm{ml}$ in complete medium and allowed to adhere in a 96-well plate overnight. Subsequently, the cells were incubated at $37^{\circ} \mathrm{C}$ for $48 \mathrm{~h}$ in the presence or absence of catumaxomab at different concentrations. After incubation, the cells were washed with a medium, followed by incubation with calcein-AM for $30 \mathrm{~min}$, and then washed again before CAT cells $(\mathrm{ET}=40: 1)$ were added to the cultures. After $4 \mathrm{~h}$ of incubation at $37^{\circ} \mathrm{C}$, the plate was washed and the adherent cells were analysed under a fluorescence microscope (IX81; Olympus, Tokyo, Japan) using Lumina Vision software (version 2.4.2; Mitani, Fukui, Japan). Images were captured with a colour CCD camera (DPI72; Olympus) and LUC plan FLN objective lens (Olympus). All procedures were performed at $20-25^{\circ} \mathrm{C}$.

Statistical analysis. All data are expressed as the mean \pm standard error of the mean (SEM) unless otherwise indicated. Differences between groups were assessed for statistical significance using the Mann-Whitney test or paired Student's $t$-test depending on the data distribution. A value of $p<0.05$ indicated statistical significance. 

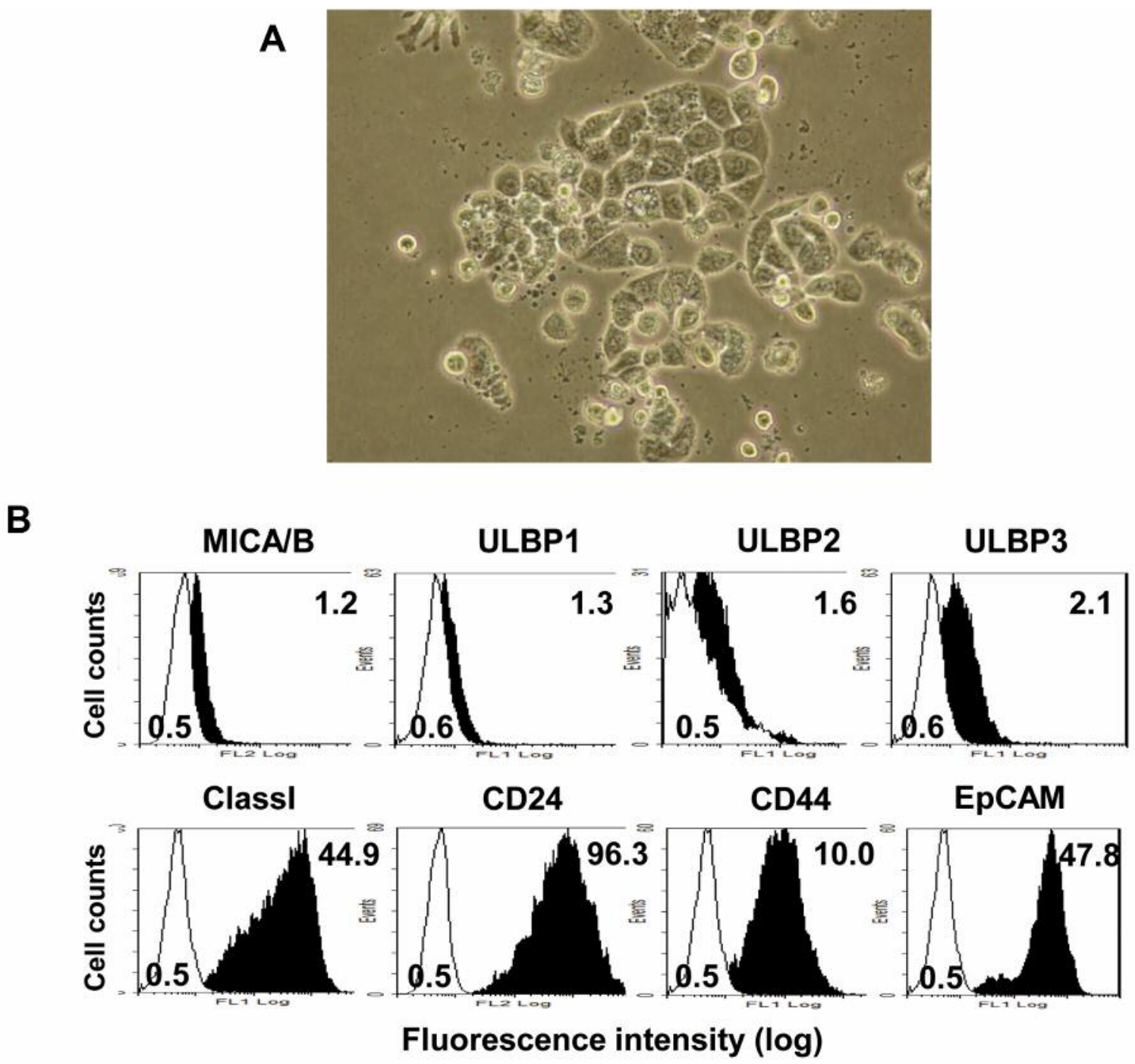

Figure 1. Characteristics of the established cell line, MUK-BC1. A: Microscopic observation of the established cell line. B: Flow cytometric analysis of surface antigens (MICA/B, ULBP1-3, ClassI, CD24, CD44, EpCAM). White: negative control, black: expression of each surface antigen. The inset number of each histogram indicates the mean fluorescence intensity.

\section{Results}

Characterization of the chemoresistant MUK-BC1 cell line. In this study, a chemoresistant TNBC cell line MUK-BC1 was established. Firstly, the cells were thoroughly examined in terms of their various properties. As shown in Figure 1A, the cells displayed an elongated and irregular spindle shape, suggesting that MUK-BC1 cells had undergone epithelialmesenchymal transition. Secondly, the breast cancer cell line was characterized by focusing on cell surface markers. The cells expressed low levels of stress antigens (MICA/B, ULBP-1, -2, and -3) and a high level of the stem-like markers CD44 and EpCAM (Figure 1B). Collectively, these results demonstrated that the MUK-BC1 cell line had CSC-like properties. Moreover, the cell line was highly resistant to several drugs (iniparib, paclitaxel, gemcitabine, olaparib and celecoxib) up to a concentration of 10-100 $\mu \mathrm{g} / \mathrm{ml}$ (Figure 2). However, cisplatin and sorafenib were effective at lower concentrations. Hence, the EpCAM which revealed the higher expression rate in TNBC was selected as the cell surface target of chemoresistant and CSLCs for immunotherapy.

Killing of MUK-BCl cells by CAT cells alone or in combination with catumaxomab. We subsequently performed in vitro cytotoxicity assays using the cell line as the target and autologous CAT cells as effectors. As shown in Figure 

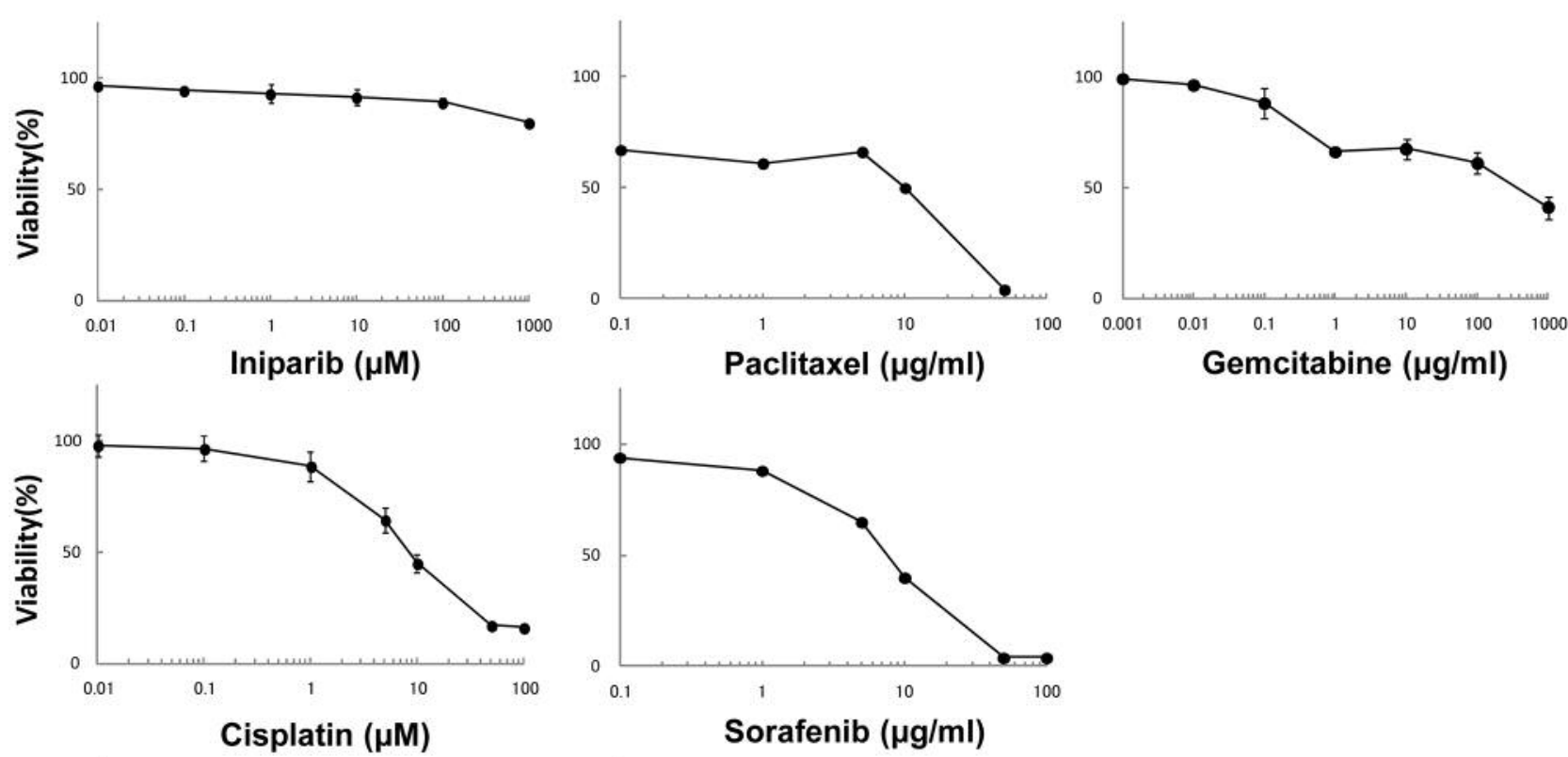

Gemcitabine ( $\mu \mathrm{g} / \mathrm{ml}$ )
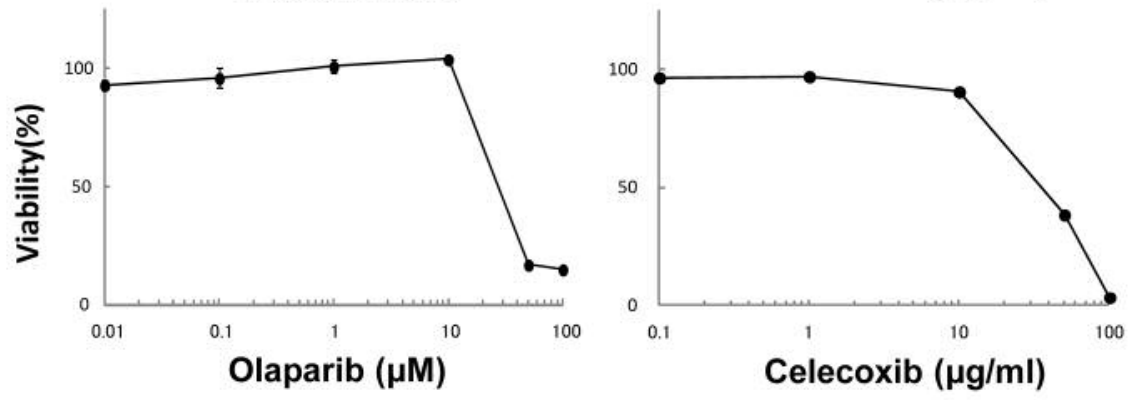

Figure 2. Effects of various types of drugs on the growth of the cell lines. Cisplatin or sorafenib were potentially effective, but the other drug was not effective at a concentration of $10 \mu \mathrm{g} / \mathrm{ml}$ in vitro.

3 , the cytotoxic assay of activated lymphocytes, $\mathrm{CD}^{+} /$ NKG2D $\mathrm{D}^{\text {high }}$ T-cells (Figure 3B), was higher compared to resting PMBCs (Figure 3A). Additionally, despite increasing the concentration of catumaxomab from 0.0001 to $10 \mathrm{ng} / \mathrm{ml}$, no inhibition of cell growth in the cell line was observed (Figure 4A). However, CAT cells led to a remarkable increase in cytotoxicity against the tumor cells in a dose- and time-dependent manner (Figure 3C). Then, it was determined whether the combination of catumaxomab and autologous CAT cells could induce cytotoxic activity against chemoresistant TNBC via ADCC, compared to catumaxomab alone. The combination of CAT cells and catumaxomab resulted in a significant increase in cytotoxicity against the tumor cells in a dose-dependent manner (Figure 4B). Incubation with $10 \mathrm{ng} / \mathrm{ml}$ catumaxomab and CAT cells $(\mathrm{E}: \mathrm{T}=20: 1)$ for $14 \mathrm{~h}$ resulted in almost complete tumor cell lysis $(p<0.01)$ (Figure $4 \mathrm{C})$. In addition, tumor cells were detached from the bottom of the well surrounded by CAT cells, and showed apoptotic changes (Figure 4C, lower panel to the right).

\section{Discussion}

A TNBC cell line termed MUK-BC1 was established, which possesses EpCAMhigh surface markers associated with chemoresistant properties. Using this cell line, it was demonstrated that catumaxomab in combination with activated T-cells eradicated chemoresistant TNBC in vitro. The results revealed that catumaxomab when combined with activated T-cells may be a novel immunotherapy for the elimination of EpCAM-expressing breast cancer cells.

TNBC cannot be treated with endocrine therapy or therapies targeted to HER2, because it is a subtype of breast tumors that lack surface markers, such as ER, PgR and HER 2 expression determined by IHC. Therefore, genomic biomarkers nowadays, tend to be considered more important than surface markers, so we assessed BRCAness in the previous study (17). TNBCs are heterogeneous and are composed of different intrinsic molecular subtypes, but some surface markers, such as basal-like (CK5/6 and/or EGFR) or programmed cell death ligand-1 defined by IHC, has become 
A

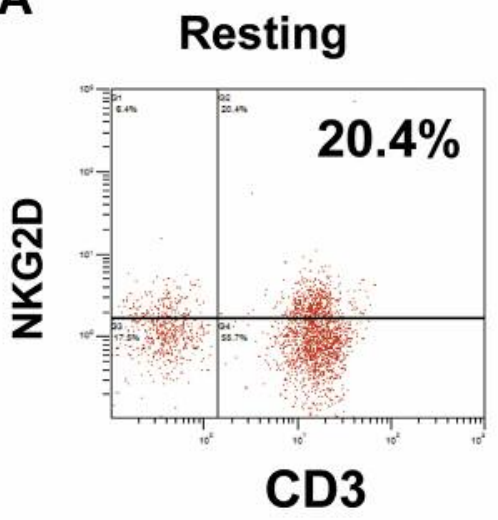

B

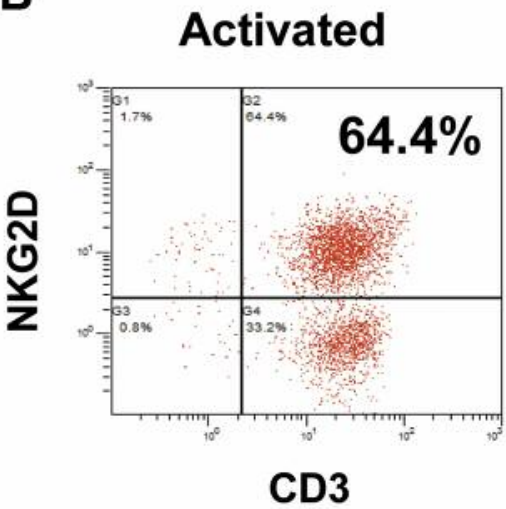

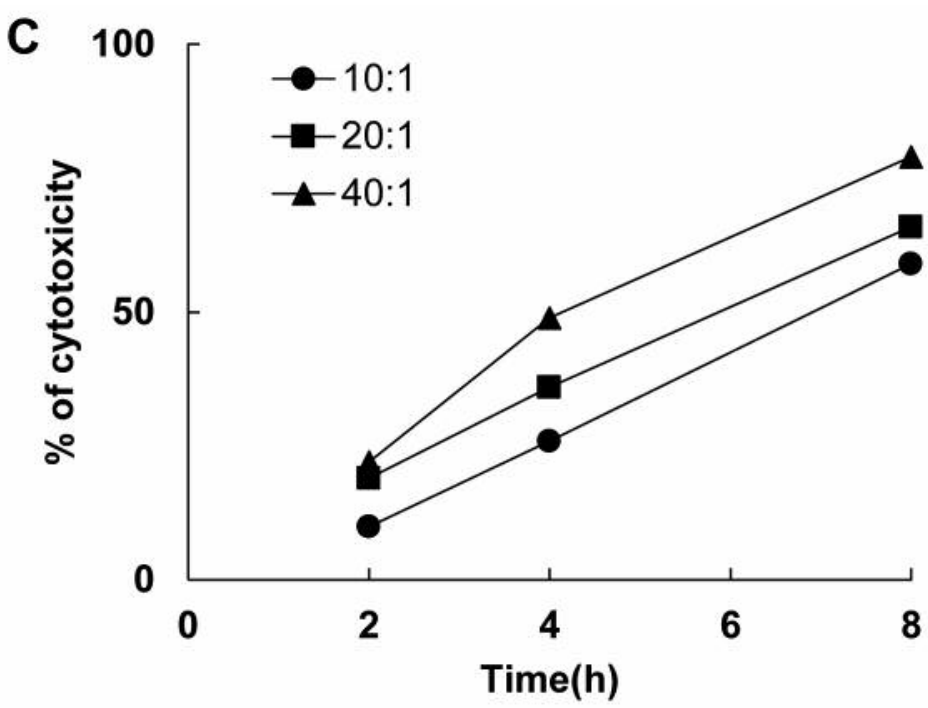
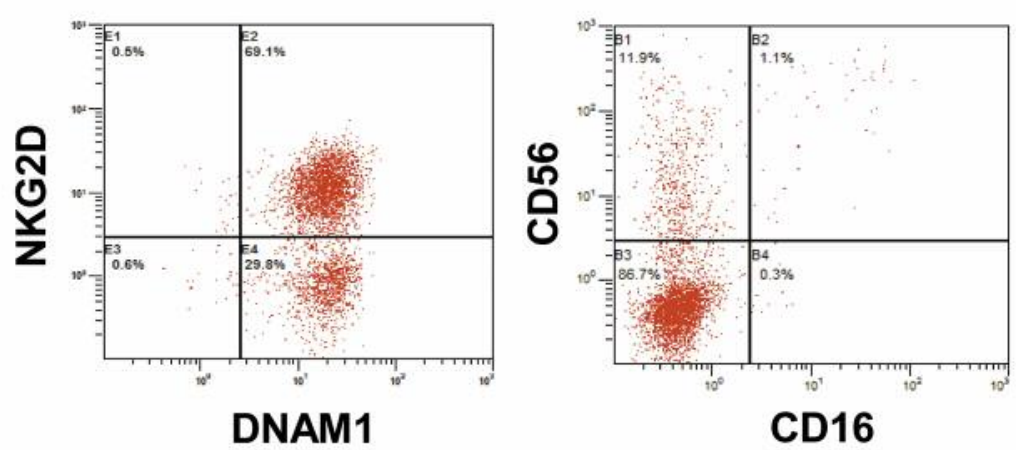

Figure 3. Flow cytometric analysis of autologous activated lymphocytes from the patient and killing of MUK-BC1 cells. A: The proportion of CD3/NKG2D-positive cells was $20.4 \%$ in resting PBMCs and B: $64.4 \%$ in activated T cells. C: Cytotoxicity increased in a dose-and a timedependent manner.

still more commonly known as the major component and the therapeutic target of TNBC $(18,19)$.

EpCAM is the best candidate for immunotherapy because it is widely and consistently expressed on the surface of tumor cells, including pancreatic, liver, breast and prostate cancer (14), without being released into circulation and at the same time associated with signalling activity (20-22). Hence, this study focused on EpCAM as the molecular target for CSLCs that developed chemoresistance. Moreover, EpCAM has been characterized as a tumor-associated antigen $(14,23)$. Recent studies on EpCAM have focused on its role in carcinogenesis (23). Research has shown that antibodies against EpCAM are effective for immunotherapeutic approaches in preclinical and clinical trials $(12,14,24)$. Since the trifunctional antibody catumaxomab effectively attaches to both EpCAM on tumour cells and CD3 on T-cells, together with binding to Fc receptors (12), the combination of T-cell therapy with catumaxomab can enhance ADCC against EpCAM-expressing tumour cells. Our study demonstrates that CAT cells together with catumaxomab have the strongest cytotoxicity against EpCAM-expressing TNBC, even after their progression to chemoresistance.

The cytotoxicity of activated T-cells is partly dependent on NKG2D/DNAM1 systems $(25,26)$. In our study, tumor cells were lysed by activated T-cells to a greater degree than by resting T-cells (data not shown), because they express more activating surface and cytotoxic molecules. Furthermore, CAT cells have shown clinical benefits when used for adoptive immunotherapy (27). Activated T-cells exhibit a greater cytotoxic effect on tumor cells than resting T-cells through the up-regulation of NKG2D expression $(28,29)$. Therefore, the combination therapy of CAT cells and catumaxomab can be promising to eliminate chemoresistant cancer cells efficiently.

These findings suggest that combination therapy of catumaxomab and activated T-cells has a potential for treating chemoresistant breast cancer. Currently, catumaxomab has been used for immunotherapy of malignant ascites, including breast cancer $(14,30)$ and reported on a pivotal clinical trial (31), which led to approval of catumaxomab for the treatment of 

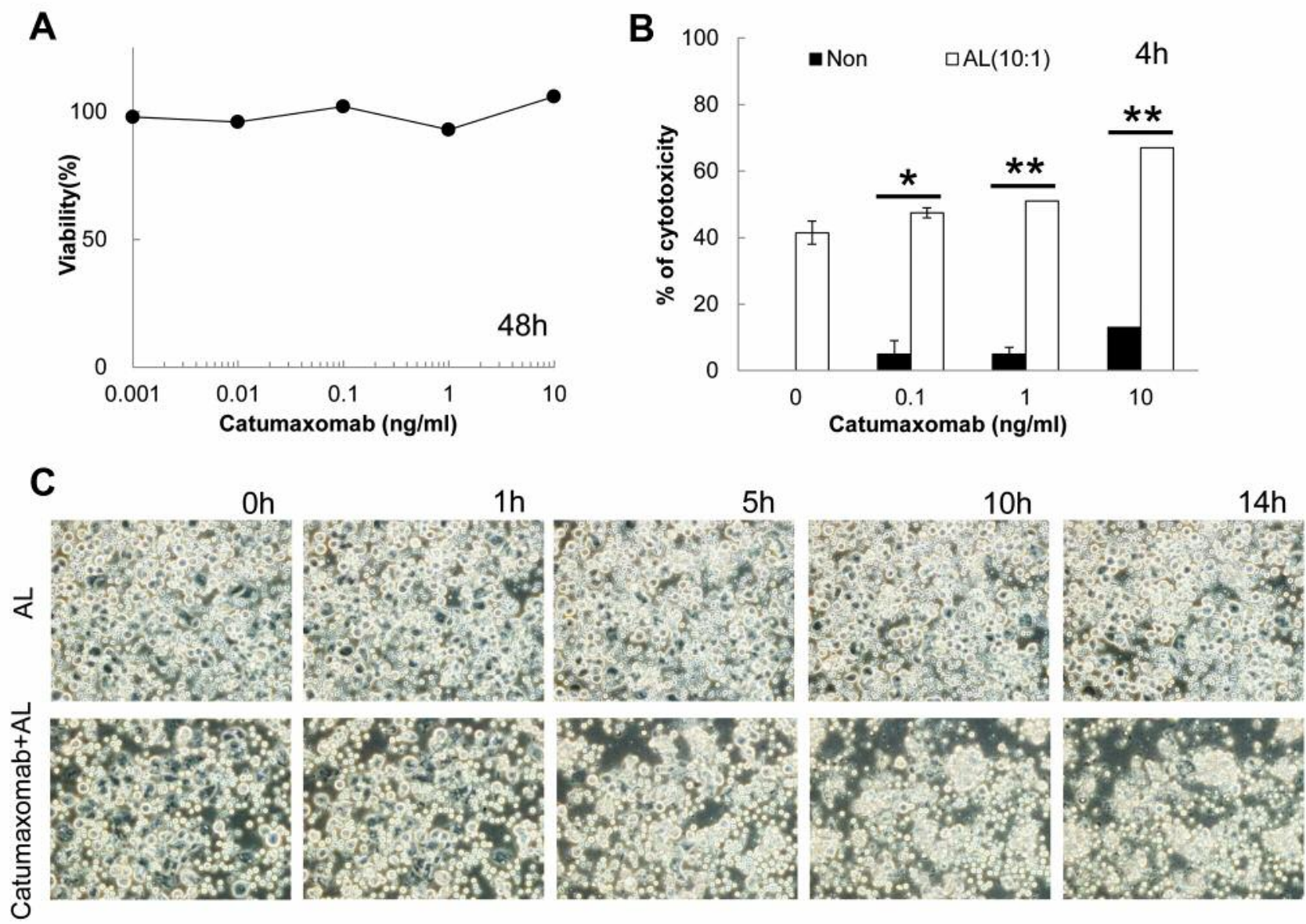

Figure 4. CAT cells and catumaxomab resulted in a significant increase in cytotoxicity against tumor cells. A: Catumaxomab did not inhibit cell growth in the cell line. B: Cytotoxic activity of catumaxomab and autologous CAT cells (AL) against chemoresistant TNBC via ADCC, compared to the combination of catumaxomab alone $(* p=0.01$ and $* * p<0.01)$. C: Time lapse $(14$ h) of cytotoxic activity by CAT cells $(E: T=20: 1)$ with or without $10 \mathrm{ng} / \mathrm{ml}$ catumaxomab for $14 \mathrm{~h}$.

malignant ascites by the European Medicines Agency in 2009. Our findings may be useful for future combination therapies using catumaxomab and adoptive T-cell immunotherapy. Noteworthy, catumaxomab was indeed capable of destroying EpCAM-expressing tumor cells in an autologous and highly immunosuppressive environment in vitro.

In conclusion, our results warrant further clinical validation by combining catumaxomab and activated T-cell therapy for patients with recurrent or drug-resistant EpCAMexpressing breast cancer.

\section{Conflicts of Interest}

There are no conflicts of interest regarding this study.

\section{Acknowledgements}

The Authors would like to thank Dr. Dongchon Kang for technical support and helpful discussions. The Authors also thank Edanz Group (www.edanzediting.com/ac) and Viva Velasquez, MD, from
St. Luke's Medical Center in Manila, Philipine for editing a draft of this manuscript.

\section{References}

1 Balzar M, Winter MJ, de Boer CJ and Litvinov SV: The biology of the 17-1A antigen (Ep-CAM). J Mol Med 77: 699-712, 1999.

2 Osta WA, Chen Y, Mikhitarian K, Mitas M, Salem M, Hannun YA, Cole DJ and Gillanders WE: EpCAM is overexpressed in breast cancer and is a potential target for breast cancer gene therapy. Cancer Res 64: 5818-5824, 2004.

3 Went P, Lugli A, Meier S, Bundi M, Mirlacher M, Sauter G and Dirnhofer S: Frequent EpCam protein expression in human carcinomas. Hum Pathol 35: 122-128, 2004.

4 Went P, Vasei M, Bubendorf L, Terracciano L, Tornillo L, Riede U, Kononen J, Simon R, Sauter G and Baeuerle PA: Frequent highlevel expression of the immunotherapeutic target Ep-CAM in colon, stomach, prostate and lung cancers. Br J Cancer 94: 128-135, 2006.

5 Munz M, Kieu C, Mack B, Schmitt B, Zeidler R and Gires O: The carcinoma-associated antigen EpCAM upregulates c-myc and induces cell proliferation. Oncogene 23: 5748-5758, 2004. 
6 Spizzo G, Went P, Dirnhofer S, Obrist P, Simon R, Spichtin H, Maurer R, Metzger U, von Castelberg B, Bart R, Stopatschinskaya S, Köchli OR, Haas P, Mross F, Zuber M, Dietrich H, Bischoff S, Mirlacher M, Sauter G and Gastl G: High Ep-CAM expression is associated with poor prognosis in node-positive breast cancer. Breast Cancer Res Treat 86: 207-213, 2004.

7 Schmidt M, Hasenclever D, Schaeffer M, Boehm D, Cotarelo C, Steiner E, Lebrecht A, Siggelkow W, Weikel W, Schiffer-Petry I, Gebhard S, Pilch H, Gehrmann M, Lehr HA, Koelbl H, Hengstler JG and Schuler M: Prognostic effect of epithelial cell adhesion molecule overexpression in untreated node-negative breast cancer. Clin Cancer Res 14: 5849-5855, 2008.

8 Cimino A, Halushka M, Illei P, Wu X, Sukumar S and Argani P: Epithelial cell adhesion molecule (EpCAM) is overexpressed in breast cancer metastases. Breast Cancer Res Treat 123: 701-708, 2010.

9 Foulkes WD, Smith IE and Reis-Filho JS: Triple-Negative Breast Cancer. N Engl J Med 363: 1938-1948, 2010.

10 Schmidt M, Petry IB, Bohm D, Lebrecht A, von Törne C, Gebhard S, Gerhold-Ay A, Cotarelo C, Battista M, Schormann W, Freis E, Selinski S, Ickstadt K, Rahnenführer J, Sebastian M, Schuler M, Koelbl H, Gehrmann M and Hengstler JG: Ep-CAM RNA expression predicts metastasis-free survival in three cohorts of untreated node-negative breast cancer. Breast Cancer Res Treat 123: 701-708, 2010.

11 Soysal SD, Muenst S, Barbie T, Fleming T, Gao F, Spizzo G, Oertli D, Viehl CT, Obermann EC and Gillanders WE: EpCAM expression varies significantly and is differentially associated with prognosis in the luminal B HER2(+), basal-like, and HER2 intrinsic subtypes of breast cancer. Br J Cancer 108: 1480-1487, 2013.

12 Schmidt M, Rüttinger D, Sebastian M, Hanusch CA, Marschner N, Baeuerle PA, Wolf A, Göppel G, Oruzio D, Schlimok G, Steger GG, Wolf C, Eiermann W, Lang A and Schuler M: Phase IB study of the EpCAM antibody adecatumumab combined with docetaxel in patients with EpCAM-positive relapsed or refractory advancedstage breast cancer. Ann Oncol 23: 2306-2313, 2012.

13 Sebastian M: Review of catumaxomab in the treatment of malignant ascites. Cancer Manag Res 8: 283-286, 2010.

14 Jäger M, Schoberth A, Ruf P, Hess J, Hennig M, Schmalfeldt B, Wimberger $\mathrm{P}$, Ströhlein $\mathrm{M}$, Theissen B, Heiss $\mathrm{MM}$ and Lindhofer H: Immunomonitoring results of a phase II/III study of malignant ascites patients treated with the trifunctional antibody catumaxomab (anti-EpCAM x anti-CD3). Cancer Res 72: 24-32, 2012.

15 Wang X, Cai J, Zhong H, Denham SA and Terasaki PI: Screening of high cytotoxic tumour killer cells using a sensitive adherent target detachment assay. J Immunol Methods 295: $57-$ 65, 2004.

16 Zhou Q, Guo AL, Xu CR, An SJ, Wang Z, Yang SQ and Wu YL: A dendritic cell-based tumour vaccine for lung cancer: fulllength XAGE-1b protein-pulsed dendritic cells induce specific cytotoxic T-lymphocytes in vitro. Clin Exp Immunol 153: 392400, 2008.

17 Mori H, Kubo M, Nishimura R, Osako T, Arima N, Okumura Y, Okido M, Yamada M, Kai M, Kishimoto J, Miyazaki T, Oda Y, Otsuka $\mathrm{T}$ and Nakamura M: BRCAness as a biomarker for predicting prognosis and response to anthracycline-based adjuvant chemotherapy for patients with triple-negative breast cancer. PLoS One 11: e0167016, 2016.
18 Prat A, Adamo B, Cheang MCU, Anders CK, Carey LA and Perou CM: Molecular characterization of basal-like and nonbasal-like triple-negative breast cancer. Oncologist 18: 123-133, 2013.

19 Mori H, Kubo M, Yamaguchi R, Nishimura R, Osako T, Arima N, Okumura Y, Okido M, Yamada M, Kai M, Kishimoto J, Oda $\mathrm{Y}$ and Nakamura M: The combination of PD-L1 expression and decreased tumor-infiltrating lymphocytes is associated with a poor prognosis in triple-negative breast cancer. Oncotarget 8 : 15584-15592, 2017.

20 Baeuerle PA and Gires O: EpCAM (CD326) finding its role in cancer. Br J Cancer 96: 417-423, 2007.

21 Patriarca C, Macchi RM, Marschner AK and Mellstedt H: Epithelial cell adhesion molecule expression (CD326) in cancer: a short review. Cancer Treat Rev 38: 68-75, 2012.

22 Imrich $S$ and Hachmeister $M$ and Gires O: EpCAM and its potential role in tumor-initiating cells. Cell Adh Migr 6: 30-38, 2012.

23 Munz M, Baeuerle PA and Gires O: The emerging role of EpCAM in cancer and stem cell signalling. Cancer Res 69: 5627-5629, 2009.

24 Cioffi M, Dorado J, Baeuerle PA and Heeschen C: EpCAM/CD3-bispecific T-cell engaging antibody MT110 eliminates primary human pancreatic cancer stem cells. Clin Cancer Res 18: 465-474, 2012.

25 Morisaki T, Onishi $\mathrm{H}$ and Katano M: Cancer immunotherapy using NKG2D and DNAM-1 systems. Anticancer Res 32: 22412247, 2012.

26 Ullrich E, Koch J, Cerwenka A and Steinle A: New prospects on the NKG2D/NKG2DL system for oncology. OncoImmunology 2(10): e26097, 2013

27 Disis ML, Bernhard H and Jaffee EM: Use of tumor-responsive T-cells as cancer treatment. Lancet 373: 673-683, 2009.

28 Morisaki T, Umebayashi M, Kiyota A, Koya N, Tanaka H, Onishi $\mathrm{H}$ and Katano $\mathrm{M}$ : Combining cetuximab with killer lymphocytes synergistically inhibits human cholangiocarcinoma cells in vitro. Anticancer Res 32: 2249-2256, 2012.

29 Morisaki T, Onishi H, Koya N, Kiyota A, Tanaka H, Umebayashi M, Ogino T, Nagamatsu I and Katano M: Combinatorial cytotoxicity of gemcitabine and cytokineactivated killer cells in hepartocellular carcinoma via the NKG2D-MICA/B system. Anticancer Res 31: 2505-2510, 2011.

30 Kurbacher CM, Horn O, Kurbacher JA, Herz S, Kurbacher AT, Hildenbrand $\mathrm{R}$ and Bollmann R: Outpatient intraperitoneal catumaxomab therapy for malignant ascites related to advanced gynecologic neoplasms. Oncologist 20: 1333-1341, 2015.

31 Heiss MM, Murawa P, Koralewski P, Kutarska E, Kolesnik OO, Ivanchenko VV, Dudnichenko AS, Aleknaviciene B, Razbadauskas A, Gore M, Ganea-Motan E, Ciuleanu T, Wimberger P, Schmittel A, Schmalfeldt B, Burges A, Bokemeyer C, Lindhofer H, Lahr A and Parsons SL: The trifunctional antibody catumaxomab for the treatment of malignant ascites due to epithelial cancer: Results of a prospective randomized phase II/III trial. Int J Cancer 127: 2209-2221, 2010.

Received April 11, 2018

Revised May 15, 2018

Accepted May 16, 2018 